\title{
Increasing thermal plant flexibility in a high renewables power system
}

Article

Accepted Version

Creative Commons: Attribution-Noncommercial-No Derivative Works 4.0

Kubik, M. L., Coker, P. J. and Barlow, J. F. (2015) Increasing thermal plant flexibility in a high renewables power system. Applied Energy, 154. pp. 102-111. ISSN 0306-2619 doi: https://doi.org/10.1016/j.apenergy.2015.04.063 Available at https://centaur.reading.ac.uk/55695/

It is advisable to refer to the publisher's version if you intend to cite from the work. See Guidance on citing.

Published version at: http://dx.doi.org/10.1016/j.apenergy.2015.04.063

To link to this article DOI: http://dx.doi.org/10.1016/j.apenergy.2015.04.063

Publisher: Elsevier

All outputs in CentAUR are protected by Intellectual Property Rights law, including copyright law. Copyright and IPR is retained by the creators or other copyright holders. Terms and conditions for use of this material are defined in the End User Agreement.

\section{www.reading.ac.uk/centaur}

\section{CentAUR}

Central Archive at the University of Reading

Reading's research outputs online 


\title{
Increasing thermal plant flexibility in a high renewables power system
}

\author{
Dr M. L. Kubik ${ }^{1}$, Dr P. J. Coker ${ }^{2 *}$ and Professor J. F. Barlow ${ }^{1}$ \\ ${ }^{1}$ Technologies for Sustainable Built Environments Centre, University of Reading, United Kingdom \\ ${ }^{2}$ School of Construction Management and Engineering, University of Reading, United Kingdom \\ * Corresponding author: p.j.coker@reading.ac.uk
}

\section{Highlights}

- Insufficient attention is given to potential flexibility of existing thermal plants

- High penetrations of variable renewable generation create curtailment and ramping challenges

- Strategies to reduce variability impacts using existing generation are identified

- Fuel switching can accommodate more renewable generation and improve system ramping capability

\begin{abstract}
Thermal generation is a vital component of mature and reliable electricity markets. As the share of renewable electricity in such markets grows, so too do the challenges associated with its variability. Proposed solutions to these challenges typically focus on alternatives to primary generation, such as energy storage, demand side management, or increased interconnection. Less attention is given to the demands placed on conventional thermal generation or its potential for increased flexibility. However, for the foreseeable future, conventional plants will have to operate alongside new renewables and have an essential role in accommodating increasing supply-side variability.

This paper explores the role that conventional generation has to play in managing variability through the sub-system case study of Northern Ireland, identifying the significance of specific plant characteristics for reliable system operation. Particular attention is given to the challenges of wind ramping and the need to avoid excessive wind curtailment. Potential for conflict is identified with the role for conventional plant in addressing these two challenges. Market specific strategies for using the existing fleet of generation to reduce the impact of renewable resource variability are proposed, and wider lessons from the approach taken are identified.
\end{abstract}

\section{Keywords:}

Variability, intermittency, conventional generation, wind curtailment, ramping, flexibility

\section{Introduction}

As variable renewable energy establishes an ever greater role in global electricity systems, so demands placed on conventional generation are changing. With modern electricity systems expected to place significant reliance on thermal plant for decades to come, there are opportunities to refine the operation of such plant to help deliver energy policy ambitions. 
Facing these evolving challenges, smaller country systems such as the island of Ireland are applying system non-synchronous penetration (SNSP) limits to ensure frequency stability and protect against unexpected supply / demand imbalances. Even smaller semi-isolated networks apply rules such as the three unit rule in Northern Ireland [1]. This squeezes out the potential for renewables to operate and drives costly curtailment. The case study of Northern Ireland is of international relevance. The ambitious renewables targets (40\% by 2020 [2]) and small mix of generators there emphasise the challenges faced in integrating high levels of variable renewables.

Whilst long-term balancing options include demand response, energy storage or increased interconnection, these are expected to have a limited impact ahead of 2020. The value of storage for addressing curtailment issues has been investigated through a number of stochastic and deterministic modelling approaches. Multiple studies have shown there is value in energy storage technology in reducing wind curtailment [3]-[5], although they disagree on the economic breakeven points for such a solution. A European wide study by Bove et al. [6] identified that energy storage requirements are strongly influenced by the system's baseload (i.e. combined minimum stable generation level). This result indicates the importance of flexibility of thermal power plants as wind penetration increases. The study also indicated that in strongly correlated wind generation areas additional interconnection might not reduce the need for storage.

Curtailing wind is undesirable for a number of stakeholders, reducing renewable energy uptake as percentage of demand and therefore limiting the possibility and increasing the cost of meeting renewable targets. This challenge has been widely acknowledged in recent research, bringing calls for greater power plant flexibility [5], [7], [8]. Under current Grid Code rules [9], the system operator has to reimburse wind generators for required curtailment. However, eliminating wind curtailment completely is not seen to be economically optimal. A level of curtailment has a role to play in reducing transmission congestion [10]-[12]. Wind curtailment can also arise for unit commitment or load balancing reasons under high wind penetrations [13], [14]. The argument has also been made that in a well-designed market, during periods of excess wind electricity prices would turn negative, giving wind power a signal for voluntary curtailment, or provide an incentive to invest in and operate other flexible technologies [15], [16].

Sudden ramping of wind power output, in either direction, can have a substantial effect on the amount of electricity generated and the types and amounts of generating units required to mitigate its variability [17]. Increased cycling of existing generation can also increase wear on units, shorten their lifespans and increase the costs of maintenance [18]. A range of wind integration studies have examined wind ramping implications, using various approaches [19][26]. These studies neglect the detailed impacts and capabilities of conventional generating plant and typically only test short time series that cannot capture the rare significant swings in wind generation. Some studies have bridged generator dispatch and the analysis of wind ramping using stochastic approaches [22], [27] but these are based on theoretical systems with simplified and aggregated characteristics, not individual plant parameters of a real system. Foley et al. [28] indicate that the impact of increasing wind ramping on the Irish grid has not received adequate attention.

This paper examines the steps that could be taken to respond to curtailment and ramping challenges introduced by variable renewables through improving existing thermal plant flexibility, a hitherto under explored area. Potentially advantageous plant modification 
strategies for an incumbent thermal coal plant are identified. An analytical approach is applied that identifies cost and carbon savings for each unit combination. This allows for analysis of local constraint parameters and tests the full range of variability seen across 32 years of wind data, rather than the fixed parameter / single year approach commonly used within power system (unit commitment \& economic dispatch) models [14], [26], [29], [30].

\section{Analysis approach and energy system simulation method}

The technical limit to acceptable wind levels without curtailment is driven by the minimum stable power level that conventional generator units can maintain whilst still satisfying system security constraints. This is known as a generator's minimum stable generation (MSG) output. This paper examines options to reduce curtailment within the NI system through reducing the local MSG. Specific attention is not given here to the all island system nonsynchronous penetration (SNSP) limit, set to ensure sufficient inertia from synchronous plant to maintain stability. EirGrid and SONI [31] suggest a limit of $75 \%$ by 2020 should be feasible, up from a current SNSP of 50\%.

\subsection{A unit by unit simulation}

Despite sharing common market trading arrangements, the Northern Ireland (NI) electricity system is operated separately from the Republic of Ireland (RoI). It consists of only a small number of generators (2.6GW of dispatchable plant and 586MW of wind) and no new conventional generation is planned [32]. It has a local peak demand of 1.8GW and wind energy currently satisfies approximately $20 \%$ of annual demand. With limited interconnection, the System Operator (TSO) applies constraints, requiring certain generators to remain on at all times. Whilst there are plans to reinforce an AC tieline with RoI, this has faced repeated delays and uncertainty [33] and NI is effectively a sub-system.

Given these constraints, close examination of must run generation is needed. A system simulation tool has therefore been developed, as detailed in Figure 1, which allows the analysis of all unit combinations, rather than seeking to solve the unit commitment problem locally e.g. [13], [14]. Combinations are sought that reduce wind curtailment by minimising the output of thermal generation. However, lower plant generation levels have the potential impact of reducing thermal efficiency (by increasing the unit's heat rate ${ }^{1}$ ) and reducing system resilience to sudden changes in wind generation. The methodology developed here thus considers the system's ability to achieve suitable ramp rates and the carbon calculations made factor in heat rate increases. Perfect foresight and full ramping capability is assumed for the calculations (i.e. that during times of high wind generation, surplus plant will be taken offline so that only the minimum security constrained on plant mix remains).

Key model inputs and parameters are:

D System demand hourly time series (MWh)

$\mathrm{W}_{\text {on }} \quad$ Onshore wind generation hourly time series (MWh)

$\mathrm{W}_{\text {off }}$ Offshore wind generation hourly time series (MWh)

$\mathrm{I}_{\mathrm{m}} \quad$ Moyle interconnector hourly limiting value (MWh)

$\mathrm{I}_{\mathrm{ns}} \quad$ North-south interconnector hourly limiting value (MWh)

\footnotetext{
${ }^{1}$ Commonly used by generating plant operators, heat rate can be thought of as the inverse of efficiency. A higher heat rate infers a low efficiency, as more energy is required to produce a unit of electricity.
} 
$\mathrm{G}_{\mathrm{msg}} \quad$ Unit minimum stable generation (MW)

$\mathrm{G}_{\max } \quad$ Unit maximum generation (MW)

$\mathrm{R}_{\mathrm{u}} \quad$ Unit upwards ramp limit (MW/min)

$\mathrm{R}_{\mathrm{d}} \quad$ Unit downwards ramp limit (MW/min)

Of the above parameters, $\mathrm{D}, \mathrm{W}_{\text {on }}$ and $\mathrm{W}_{\text {off }}$ are dynamic values, whilst the others are static constraints of either the generation unit in question or of the system, as defined in Section 3.

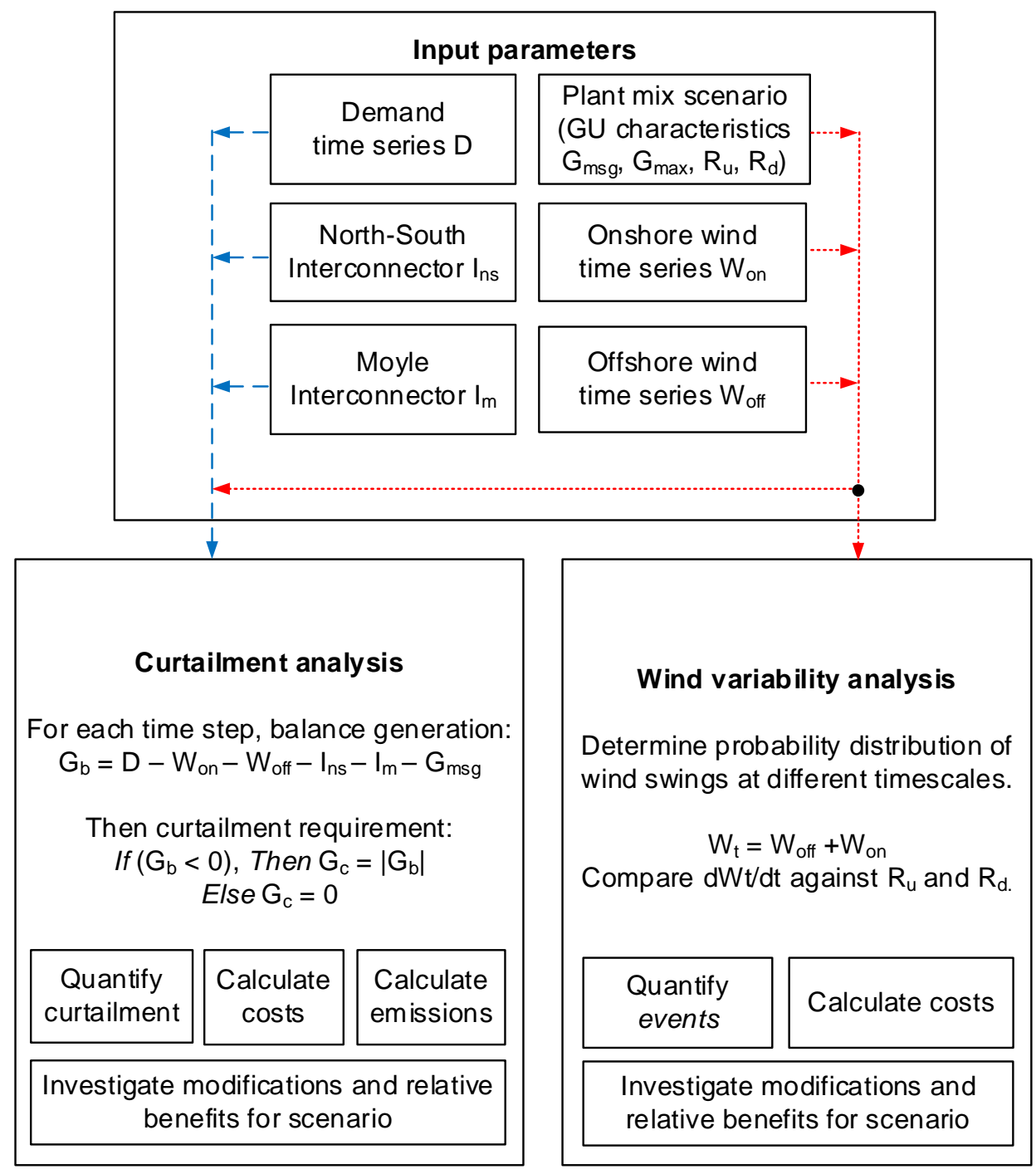

Figure 1 - System representation used to calculate wind curtailment and wind ramping events

(the short dashed line indicates inputs common to both analyses, the long dashed line indicates inputs only used in the curtailment analysis)

\subsection{Testing for curtailment and ramping}

\subsubsection{Curtailment calculation}

Six input parameters introduced in Section 2.1 are used to determine the necessary balance of conventional generation $G_{b}$ to create a balance of supply and demand for each half hour:

$$
G_{b}=D-W_{o n}-W_{o f f}-I_{n s}-I_{m}-G_{m s g}
$$


When $G_{b}$ is negative (i.e. there is surplus supply to satisfy demand for any given half hourly period), this is assumed to be resolved by the system operator through curtailment $\left(G_{c}\right)$ of the wind generation:

$$
G_{c}=\left|G_{b}\right| \text { if } G_{b}<0
$$

\subsubsection{Emissions calculation}

The savings in carbon emissions when moving from one system MSG condition to another are calculated considering both the reduction in conventional generation and the change in carbon intensity of the generation mix. The average annual fuel carbon intensities are taken as those for the Irish SEM in 2010 (Table 1).

During periods where conventional generators are operating at minimum generation levels, carbon equivalent emissions are higher than average intensities, as plant efficiency is lower at lower loads [34], [35]. This was accounted for in the modelling of carbon emissions by applying an intensity adjustment factor for each NI unit based upon the percentage difference between heat rate at minimum stable generation and at the unit's design heat rate. These adjustments to individual units are presented in the data section and are listed in Table 4.

Table 1 - Emissions factors used in the analysis, based upon 2010 SEM data

\begin{tabular}{|c|c|}
\hline Fuel & $\mathbf{~ k g C O}_{\mathbf{2}} \mathbf{e q} / \mathbf{M W h}$ \\
\hline Oil & 833 \\
\hline Coal & 1015 \\
\hline Gas & 433 \\
\hline Wind & $21^{\mathrm{i}}$ \\
\hline
\end{tabular}

i.Wind emissions factor is a life cycle value based upon Lenzen [36].

\subsubsection{Cost calculation}

Wind curtailment has multiple financial impacts. Considered from a system operators perspective, the cost impact combines the system payment for curtailed wind energy and payment for conventional generation constrained on. There is also lost Renewable Obligation Certificate (ROC) revenue for wind generators, but this represents an opportunity cost rather than one passed on to consumers and hence is not included in this calculation. The historical cost of wind curtailment is estimated from publically available commodity, carbon price, and system marginal price data published by SEMO [37]. The cost calculations presented in this paper look retrospectively over these to identify present day solutions to reducing system MSG under the three-generator unit rule.

System curtailment costs for constrained off wind energy were calculated as follows:

$$
C_{S Y S}=\sum_{i=1}^{N} \mathrm{SMP}_{\mathrm{i}} \cdot \mathrm{G}_{\mathrm{ci}}
$$

Where $\mathrm{i}$ is the half hourly period of the annual time series, $\mathrm{N}$ is the total number of half hours (17520), and $\mathrm{SMP}_{\mathrm{i}}$ and $\mathrm{G}_{\mathrm{ci}}$ are the historic SMP price ( $\left.£ / \mathrm{MWh}\right)$ and the amount of curtailment (MWh) at each time step. 
The constrained on $^{2}$ running costs for Kilroot were calculated using:

$$
C_{\text {CON }}=\sum_{i=1}^{N}\left(\dot{m}_{\text {coal }} \cdot P_{\text {coali }}\right)+\left(\dot{m}_{\text {oil }} \cdot P_{\text {oili }}\right)
$$

Where $\dot{m}_{\text {coal }}$ and $\dot{m}_{\text {oil }}$ were the fuel flow rates required (in tonnes per half hour) to sustain MSG of one of Kilroot's units (Table 2), and $P_{\text {coali }}$ and $P_{\text {oili }}$ were the average historical commodity prices $(£ / t)$ for the fuel for each ith half-hourly period in the annual time series.

Table 2 - Fuel flow rate for Kilroot to supply MSG under possible operation regimes

\begin{tabular}{|l|l|l|l|l|l|}
\hline Unit ID & Description & $\begin{array}{l}\text { Generated } \\
\text { (MW) }\end{array}$ & $\begin{array}{l}\text { Sent out } \\
\text { (MW) }\end{array}$ & $\begin{array}{l}\text { Coal } \\
\text { (kg/s) }\end{array}$ & $\begin{array}{l}\text { Oil } \\
\text { (kg/s) }\end{array}$ \\
\hline K1,K2 & Coal (3 mills) & 110 & 93 & 11.75 & 0.00 \\
\hline K_C & Reduced coal (2 mills) & 80 & 64 & 8.00 & 0.00 \\
\hline K_CO & Coal + continual oil support & 70 & 53 & 4.25 & 1.50 \\
\hline K_O & Oil & 60 & 45 & 0.00 & 4.00 \\
\hline
\end{tabular}

Finally, the savings due to reduced cost of carbon were calculated using:

$$
C_{C A R B}=\sum_{i=1}^{N} \mathrm{C}_{\text {netl }} \cdot \mathrm{P}_{\text {carbi }}
$$

Where $\mathrm{C}_{\text {net }}$ are the net carbon emission (in $\mathrm{tCO}_{2 \mathrm{eq}}$ ) saved due to reducing the MSG for each ith half hourly period, and $\mathrm{P}_{\text {carbi }}$ is the average carbon price for the same half hourly period.

\subsubsection{Ramping calculation}

A ramping event in this paper is defined as a change in wind generation output greater than the ability of conventional generation alone (excluding peaking generation) to respond. The change in wind generation in the input time series in each case was calculated over each time step to give an average rate of change in wind generation for each hour:

$$
\frac{d W_{t}}{d t}=\frac{W_{t+1}-W_{t}}{t}
$$

$\mathrm{W}_{\mathrm{t}}$ is the wind generation at a particular time step $\mathrm{t}$, and $\mathrm{W}_{\mathrm{t}+1}$ is the wind generation at the next time step $t+1$. Positive wind ramping is hence defined as those where wind generation is consecutively increasing ( $\mathrm{dW}_{\mathrm{t}} / \mathrm{dt}$ is positive) and negative ramping when wind generation is decreasing $\left(\mathrm{dW}_{\mathrm{t}} / \mathrm{dt}\right.$ is negative).The wind ramp rates were then compared to the upward or downward ramping threshold $\left(\mathrm{R}_{\mathrm{U}}\right.$ and $\left.\mathrm{R}_{\mathrm{D}}\right)$ for each unit scenario.

\subsection{Thermal coal plant modifications considered}

The coal plant considered in this study, Kilroot power station, was commissioned in Northern Ireland in 1981. It was originally built as an oil plant, but was converted to allow coal and oil fuel flexibility. Since its conversion, it has run predominantly on coal due to favourable

\footnotetext{
${ }^{2}$ When a generator is constrained on in the Irish SEM it only gets paid its fuel costs for running, rather than the system marginal price of electricity. It is effectively running at a breakeven cost. The cost of constrained running therefore varies only as fuel costs vary.
} 
commodity prices. Discussions with Northern Ireland plant operators have identified Kilroot as a key plant where technically feasible modifications can be made to enhance flexibility.

A coal plant's minimum stable generation depends on the quality of the fuel blend when dispatched on coal. Coals are often sourced from multiple locations with different characteristics (e.g. low sulphur coals), and with different levels of homogeneity. A more consistent and predictable delivery of pulverised coal makes it easier for the low flow rates needed for minimum generation. At least three mills are required to provide the pulverised fuel needed to operate a unit stably.

A significant problem with mill reliability at low loads lies with the failsafes that govern its operation. At lower generation levels, the risk of failing to detect a flame is notably higher, due to the weaker intensity of fuel injection. Introducing an improved burner management system and improving flame scanner detection instrumentation would allow the plant to operate its units on coal using fewer mills, reducing its MSG to 64MW (K_C in Table 3).

Alternatively, the plant could be operated using one mill with continual oil support at a reduced MSG of 53MW (K_CO in Table 3), without modification. Such a running regime is more reliable than coal alone as the combustion in the boiler is oil rather than coal controlled, minimising the risk of a mill trip as its coal and air flow rates can be fixed.

Finally, the plant could run on oil alone, with the option of switching back to coal operation when stable operational conditions for coal are reached (K_O in Table 3). Heavy fuel oil (HFO) can burn at much lower mass flow rates without the flame detection or mill stability problems of coal; Kilroot is able to generate as low as $45 \mathrm{MW}$ per unit on oil firing alone. Increased oil firing would require investment in the burner system to improve burner reliability as well as a review of emissions implications for the plant ${ }^{3}$.

Table 3 - Summary of Kilroot (thermal coal plant) modification scenarios considered

\begin{tabular}{|l|l|l|l|}
\hline Regime & Description & Advantages & Disadvantages \\
\hline K1/K2 & $\begin{array}{l}\text { Existing dispatch of } \\
\text { Kilroot units, running with } \\
\text { three coal mills. }\end{array}$ & $\begin{array}{l}\text { Coal much cheaper } \\
\text { commodity than oil. Three } \\
\text { mills allow some redundancy } \\
\text { against mill trips. }\end{array}$ & $\begin{array}{l}\text { Low flexibility: high MSG } \\
\text { relative to potential alternatives, } \\
\text { slow ramping. }\end{array}$ \\
\hline K_O & $\begin{array}{l}\text { Modify Kilroot to } \\
\text { optimise for dispatch on } \\
\text { oil at MSG. }\end{array}$ & $\begin{array}{l}\text { Significant range between } \\
\text { Gmax }_{\text {mand Gms, rapid ramp up }} \\
\text { and down. HFO has lower } \\
\text { CO }_{\text {2eq }} \text { emissions. }\end{array}$ & $\begin{array}{l}\text { High commodity cost of HFO, } \\
\text { improvement in oil burner } \\
\text { reliability necessary. Different } \\
\text { emissions and environmental } \\
\text { considerations. }\end{array}$ \\
\hline K_CO & $\begin{array}{l}\text { Boiler to run on one mill, } \\
\text { but with continual oil } \\
\text { firing to support flame. }\end{array}$ & $\begin{array}{l}\text { Single mill allows } \\
\text { considerable MSG reduction. } \\
\text { Oil burner support improves } \\
\text { ramp up/down flexibility and } \\
\text { reliability. }\end{array}$ & $\begin{array}{l}\text { High commodity cost of HFO. } \\
\text { Coal and oil mixture can cause } \\
\text { blockages leading to tube leaks. }\end{array}$ \\
\hline K_C & $\begin{array}{l}\text { Improve flame scanners to } \\
\text { allow Kilroot to run } \\
\text { supported by two coal } \\
\text { mills alone. }\end{array}$ & $\begin{array}{l}\text { Coal a much cheaper } \\
\text { commodity than oil. }\end{array}$ & $\begin{array}{l}\text { Modification required, non- } \\
\text { homogeneity of coal makes } \\
\text { ramping difficult and limits } \\
\text { achievable MSG reduction. Mill } \\
\text { trip hazard. }\end{array}$ \\
\hline
\end{tabular}

\footnotetext{
${ }^{3} \mathrm{HFO}$ is cleaner than coal in terms of $\mathrm{CO}_{2}$ equivalent emissions, but the post combustion scrubbing of the boiler gas at Kilroot is designed for coal use.
} 


\section{The Northern Ireland Case: market specific restrictions and data}

This section outlines market specific system restrictions and constraints, and outlines how data was selected or simulated for use within the model parameters introduced in Section 2.

\subsection{Market restrictions}

Presently, Northern Ireland requires at least three generators to be synchronised with the grid at any one time for security [1]. Further local constraints exist, for example, requiring one Kilroot unit to be on at all times for voltage support (due to its proximity to Belfast) and one at Coolkeeragh power station in the north west of the province. These additional system constraint rules create two feasible minimum-security requirement scenarios, which are introduced later in this data section as 'business as usual' base cases (Section 3.5).

Whilst fuel switching can increase flexibility, the option of running plant on oil for low loads and switching to cheaper coal when an economic threshold is reached is not feasible within the existing market scheduling rules. The current Irish market framework prevents start up on a more expensive fuel, as bids have to be monotonically increasing. This means that a bid for more generation from the same unit has to be for a larger amount of money than for less generation (Figure 2). The changes leading up to 2017 market reform to comply with the EU Target Model may be timely for this market scheduling issue to be addressed.

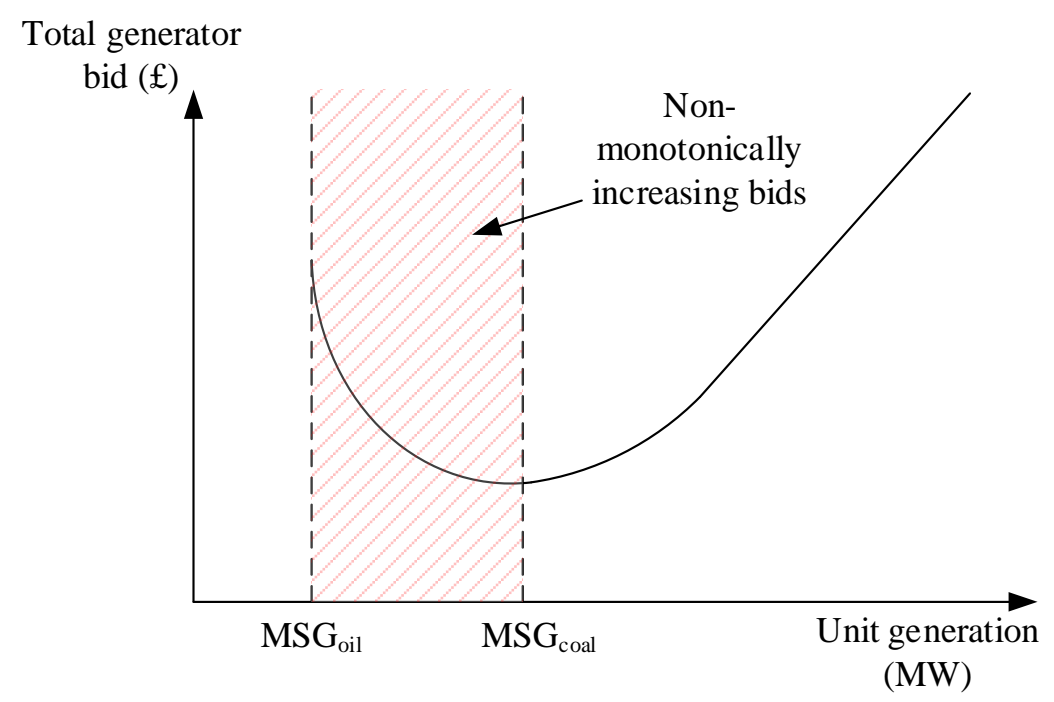

Figure 2 - Schematic cost curve bid profile for Kilroot starting on oil and phasing in coal until the minimum coal dispatch threshold is achieved 
Demand in 2020 was simulated based upon EirGrid and SONI's [38] growth projections by applying linear growth to the 2009 demand time series. The year 2009 was selected for its close match to the long-term average wind capacity factor.

\subsection{Onshore and offshore wind}

Onshore and offshore wind generation were simulated, drawing on 32 years of hourly wind speed data from NASA-GMAO's MERRA reanalysis dataset. Wind speeds at $10 \mathrm{~m}$ from ground level were obtained for seven well-spaced onshore sites and one offshore site then adjusted to represent an appropriate hub height. Installed capacities of 1030MW of onshore and 600MW of offshore wind were assumed, in line with EirGrid and SONI's [38] projections for 2020, with an average onshore turbine assumed to be $60 \mathrm{~m}$ hub height and 2MW capacity and offshore of $80 \mathrm{~m}$ and 3MW capacity. The time series was linearly interpolated to half hourly generation values to match the resolution of the demand series data. This procedure is described more fully in [39].

\subsection{Interconnectors}

Limiting flows are applied to represent the north-south interconnector to RoI and the underwater, HVDC Moyle interconnector which links NI to the Great Britain transmission system. A range of interconnection scenarios were stress tested but for the analysis reported in this paper, a central scenario based on historical average export flows was considered with $\mathrm{I}_{\mathrm{m}}+\mathrm{I}_{\mathrm{ns}}=450 \mathrm{MW}$.

\subsection{Plant operational parameters and scenarios}

Operational parameters for NI's conventional generation are shown in Table 4. Unit characteristics are also given representing possible modifications to the Kilroot coal plant introduced in Section 1. Generator units that are to be decommissioned by 2020 have been omitted.

As mentioned in Section 3.1, Northern Ireland requires at least three generators to be synchronised with the grid at any one time for security [1]. Further transmission constraint rules restrict the system to two minimum-security requirement 'business as usual' scenarios, which are considered in this paper: B-Low and B-High (i.e. business as usual low and business as usual high).

A further 26 generator scenarios considered in this analysis are shown in Table 5; these cover the generator unit combinations from Table 4 that can satisfy the security constraint rules as well as the modifications described in Section 2.3. All possible two-unit generation combinations are also investigated under the assumption of further network developments relaxing existing constraints. 
Table 4 - Northern Ireland individual generator unit characteristics, including thermal plant modification characteristics for Kilroot power station described in Table 3 (source: SEMO market data)

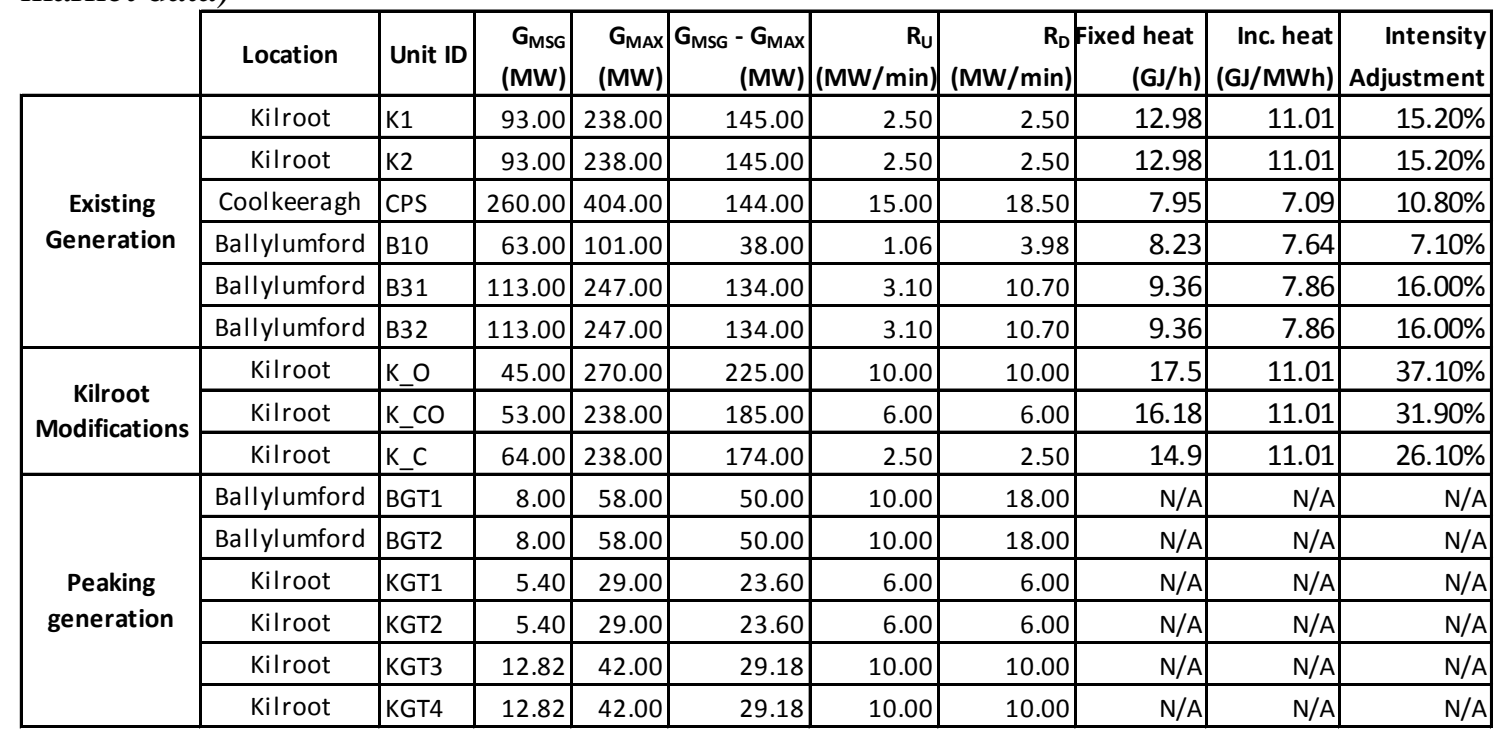

Table 5 - Generator unit scenarios considered ${ }^{4}$

\begin{tabular}{|c|c|c|c|c|c|c|c|c|}
\hline \multirow[b]{2}{*}{ Scenarios } & \multirow[b]{2}{*}{ Unit 1} & \multirow[b]{2}{*}{ Unit 2} & \multirow[b]{2}{*}{ Unit 3} & \multirow{2}{*}{$\begin{array}{l}\text { Combined } \\
\text { MSG (MW) }\end{array}$} & \multicolumn{2}{|c|}{ Combined Ru $(\mathrm{MW} / \mathrm{t})^{*}$} & \multicolumn{2}{|c|}{ Combined Rd (MW/t)* } \\
\hline & & & & & $t=1 \mathrm{hr}$ & $\mathrm{t}=4 \mathrm{hr}$ & $t=1 \mathrm{hr}$ & $t=4 \mathrm{hr}$ \\
\hline B-Low & CPS & K1 & K1 & 446 & 434 & 434 & 434 & 434 \\
\hline B-High & CPS & K1 & B31 & 466 & 423 & 423 & 423 & 423 \\
\hline Sc1 & CPS & K_O & K_O & 350 & 594 & 594 & 594 & 594 \\
\hline Sc2 & CPS & K_O & B31 & 418 & 503 & 503 & 503 & 503 \\
\hline Sc3 & CPS & K_CO & K_CO & 366 & 514 & 514 & 514 & 514 \\
\hline Sc4 & CPS & K_CO & B31 & 426 & 463 & 463 & 463 & 463 \\
\hline Sc5 & CPS & K_C & K_C & 388 & 444 & 444 & 444 & 444 \\
\hline Sc6 & CPS & K_C & B31 & 437 & 428 & 428 & 428 & 428 \\
\hline Sc7 & CPS & K1 & & 353 & 289 & 289 & 289 & 289 \\
\hline Sc8 & CPS & K_O & & 305 & 369 & 369 & 369 & 369 \\
\hline Sc9 & CPS & K_C & & 324 & 294 & 294 & 294 & 294 \\
\hline Sc10 & CPS & K_CO & & 313 & 329 & 329 & 329 & 329 \\
\hline Sc11 & CPS & B31 & & 373 & 278 & 278 & 278 & 278 \\
\hline Sc12 & CPS & B10 & & 323 & 182 & 182 & 182 & 182 \\
\hline Sc13 & K1 & B31 & & 206 & 279 & 279 & 279 & 279 \\
\hline Sc14 & K1 & B10 & & 156 & 183 & 183 & 183 & 183 \\
\hline Sc15 & K1 & K1 & & 186 & 290 & 290 & 290 & 290 \\
\hline Sc16 & K_O & B31 & & 158 & 359 & 359 & 359 & 359 \\
\hline Sc17 & K_O & B10 & & 108 & 263 & 263 & 263 & 263 \\
\hline Sc18 & K_O & K_O & & 90 & 450 & 450 & 450 & 450 \\
\hline Sc19 & K_C & B31 & & 177 & 284 & 284 & 284 & 284 \\
\hline Sc20 & K_C & B10 & & 127 & 188 & 188 & 188 & 188 \\
\hline Sc21 & K_C & K_C & & 128 & 300 & 300 & 300 & 300 \\
\hline Sc22 & K_CO & B31 & & 166 & 319 & 319 & 319 & 319 \\
\hline Sc23 & K_CO & B10 & & 116 & 223 & 223 & 223 & 223 \\
\hline Sc24 & K_CO & K_CO & & 106 & 370 & 370 & 370 & 370 \\
\hline Sc25 & B31 & B10 & & 176 & 172 & 172 & 172 & 172 \\
\hline Sc26 & B31 & B32 & & 226 & 268 & 268 & 268 & 268 \\
\hline
\end{tabular}

*All units are able to ramp their maximum range over one hour

\footnotetext{
${ }^{4}$ Units K1 and K2 are equivalent, as are B31 and B32. Repeated combinations for K2 and B32 are therefore not shown in the table.
} 


\section{Results}

\subsection{Wind curtailment}

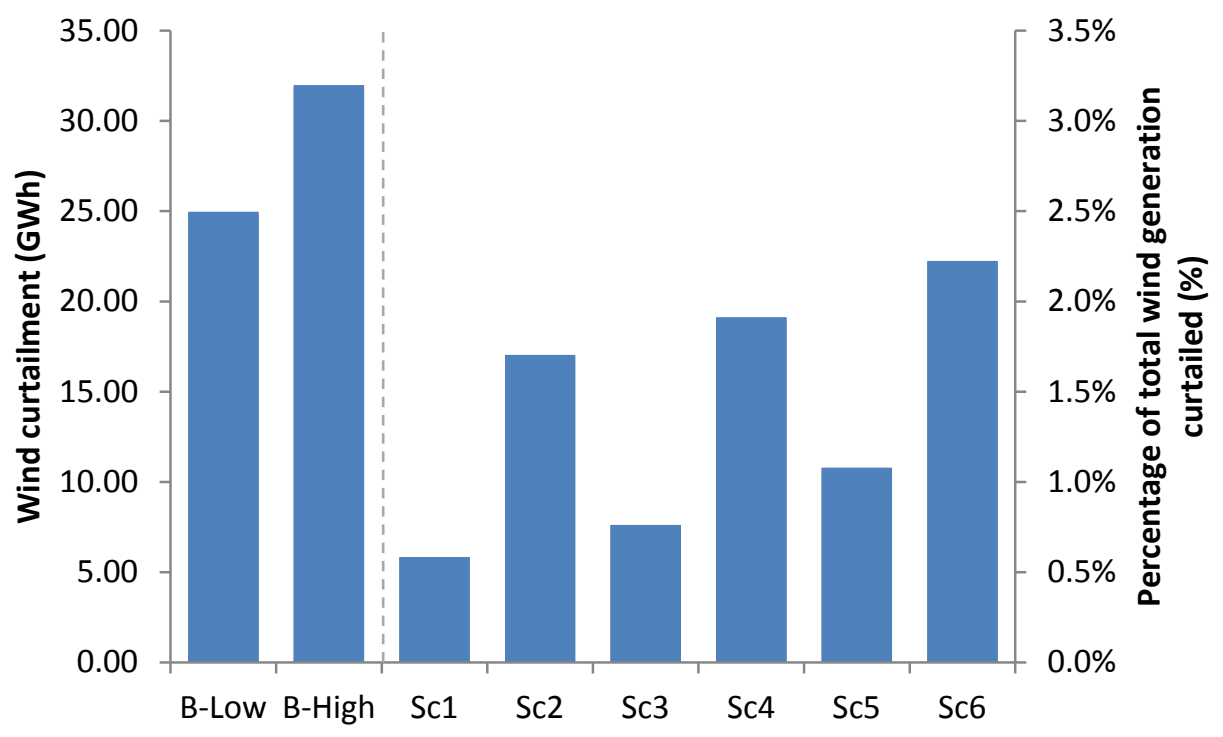

Figure 3 - 2011 Northern Ireland wind curtailment levels under business as usual conditions and under six modified operational regimes

Figure 3 shows that for 2011 the curtailment level estimated by this analysis was between 2532GWh (around 2.5-3.2\% of total wind generation). These results were validated using market data comparing dispatch quantity (DQ) and market schedule quantity (MSQ) data for the NI wind units [37], which revealed that directly measured curtailment in Northern Ireland was $2.85 \%$ in 2011, in the middle of this predicted range. This validation gives confidence that the modelling approach is able to determine curtailment levels successfully.

The benefit of operating Kilroot under the six different running regimes (Sc1 to Sc6) is also shown in Figure 3, demonstrating that all scenarios provide some reduction to wind curtailment, with the most substantial reduction in Sc1 (a combination using two oil-modified Kilroot units as shown in Table 5).

Figure 4 illustrates the net financial saving of these scenarios relative to business as usual scenario B-High. Whilst scenario Sc1 offers the largest reduction to wind curtailment, the savings associated with this are actually outweighed by the high cost of fuel oil and would result in marginally increased system costs of $£ 97,000$ per year. All other modification scenarios produce a net financial benefit, with Sc5 (a combination using two reduced coal output modifications shown in Table 5 ) saving $£ 1.8 \mathrm{~m}$ per year.

In contrast, the net savings of carbon (Figure 5) for these six scenarios is broadly reversed with the largest reduction possible being 16-20 ktCO ${ }_{2}$ eq on oil firing (Sc1 and Sc2) and Sc5 performing the worst by actually increasing emissions relative to the business as usual case by $3.5 \mathrm{ktCO}_{2}$ eq. This is due to the reduced efficiency of part-loaded coal plant (the most carbon intensive fuel in NI: see Table 1) outweighing the carbon saved by reducing wind curtailment. 


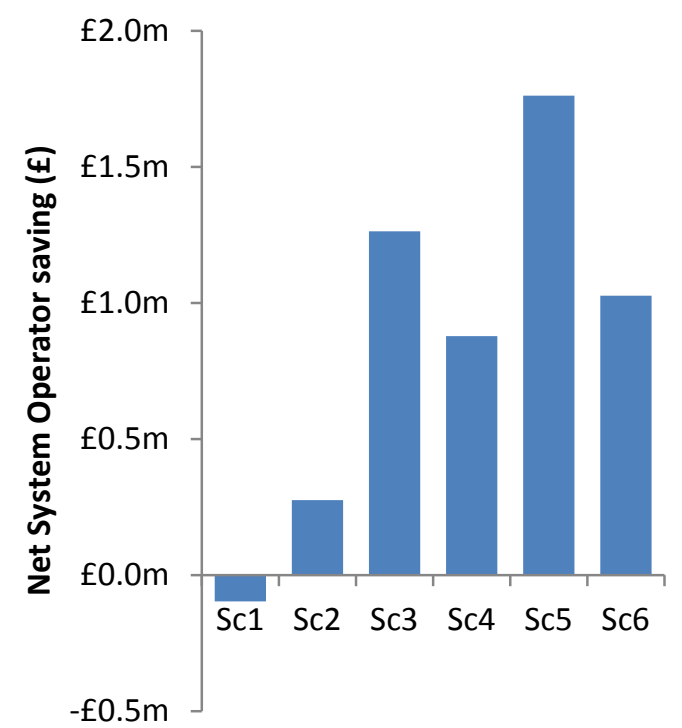

Figure 4 - Net financial benefit of reducing 2011 wind curtailment using proposed modifications in scenarios 1 to 6

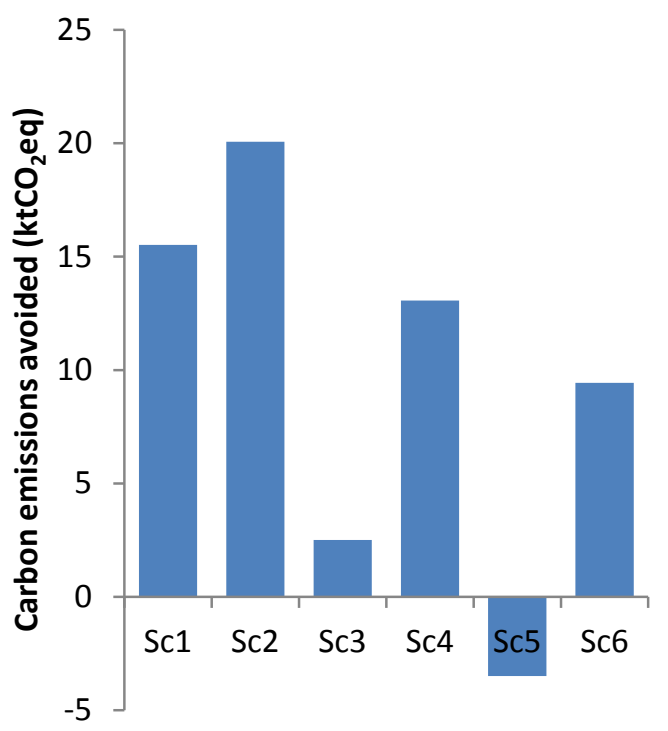

Figure 5 - Carbon emissions avoided by reducing 2011 wind curtailment using proposed modifications in scenarios 1 to 6

The results of all 28 scenarios under 2020 levels of installed wind generation are shown in ranked order in Figure 6. Under existing system security constraints, the Northern Ireland system would be required to curtail approximately 350GWh of wind generation in order to readdress the balance of supply and demand, some 7.0-7.5\% of total unconstrained wind generation. With the utilisation of Kilroot's dual fuel flexibility during times of high wind generation, even with the 3-unit system security rule enforced, it is possible to reduce this level of curtailment to $4.9 \%$ on oil (Sc1), 5.3\% on coal with oil support (Sc3) and 5.7\% with reduced coal modifications (Sc5). Possible two unit configurations were considered, showing reductions of up to $79 \%$ to curtailment requirements relative to B-High were possible (Sc18).

The savings of emissions in $\mathrm{ktCO}_{2} \mathrm{eq}$, relative to business as usual scenario B-High, are shown in Figure 7. The findings broadly follow those of Figure 6, with lower curtailment levels saving the most on carbon emissions. However, the reduced operational efficiency at lower minimum generations leads to increased carbon intensity and limits the emissions savings of some of the lower MSG scenarios.

Whilst Figure 6 and Figure 7 identify that the best achievable levels of curtailment and emissions savings are $1.6 \%$ (Sc18) and $202 \mathrm{ktCO}_{2 \mathrm{eq}}(\mathrm{Sc} 25)$ respectively, there are further concerns that may dissuade the system operator from considering them for constrained running. Of particular note, scenarios that include units sharing a common grid connection point increase the risk of losing both units simultaneously, whilst other scenarios reduce the ramping capability on the system. These scenarios are highlighted with diagonal hatching and horizontal hatching respectively in Figure 6 and Figure 7. 


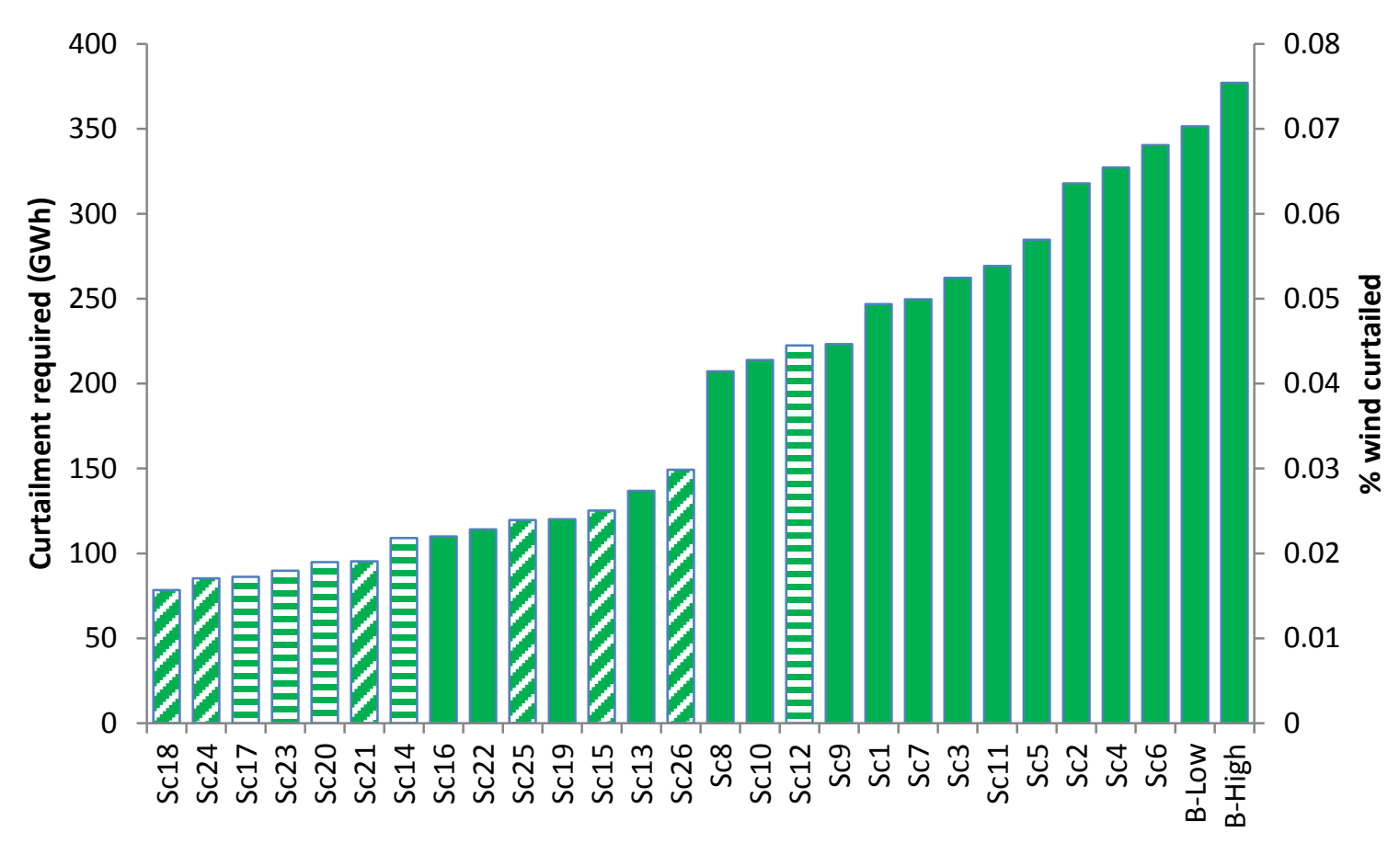

Figure 6 - Scenarios ranked with respect to wind curtailment levels and identifying system security concerns

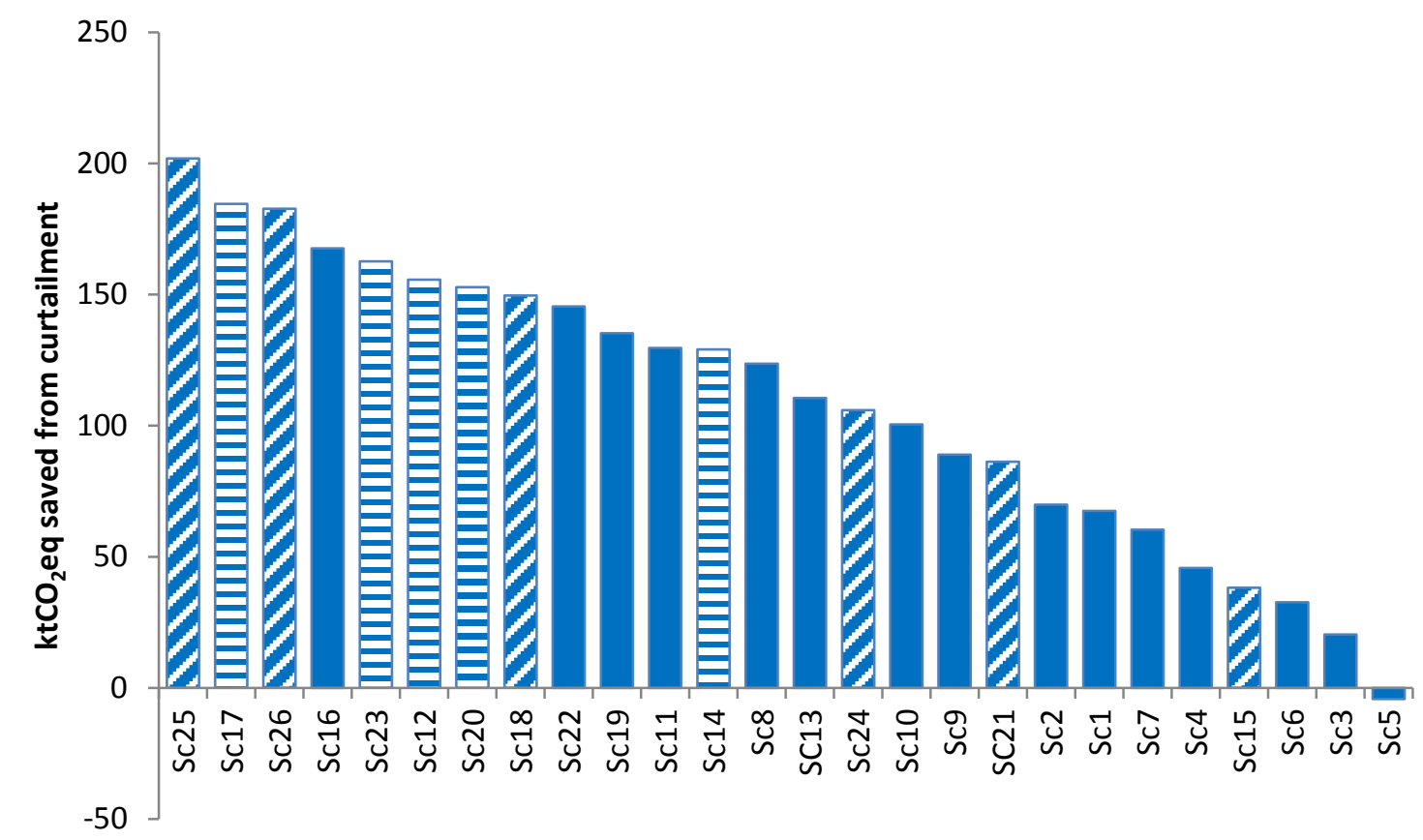

Figure 7 - Scenarios ranked with respect to carbon emissions savings and identifying system security concerns

A correlation between the curtailment and emissions savings levels for the various scenarios is plotted in Figure 8. This demonstrates that the relationship between lower levels of wind curtailment and high emissions savings is weak (0.45), and strongly dependent on the type of conventional generation providing the reduction. The importance of considering the inefficiency of part loaded plant is demonstrated by Sc5, which consisted of two Kilroot units running on minimum coal; whilst this reduces the level of wind curtailment on the system it 
would result in a marginal net increase in carbon emissions. The gradient of the line implies a relationship of approximately $0.45 \mathrm{ktCO}_{2} \mathrm{eq}$ saved for every GWh of wind that avoids curtailment.

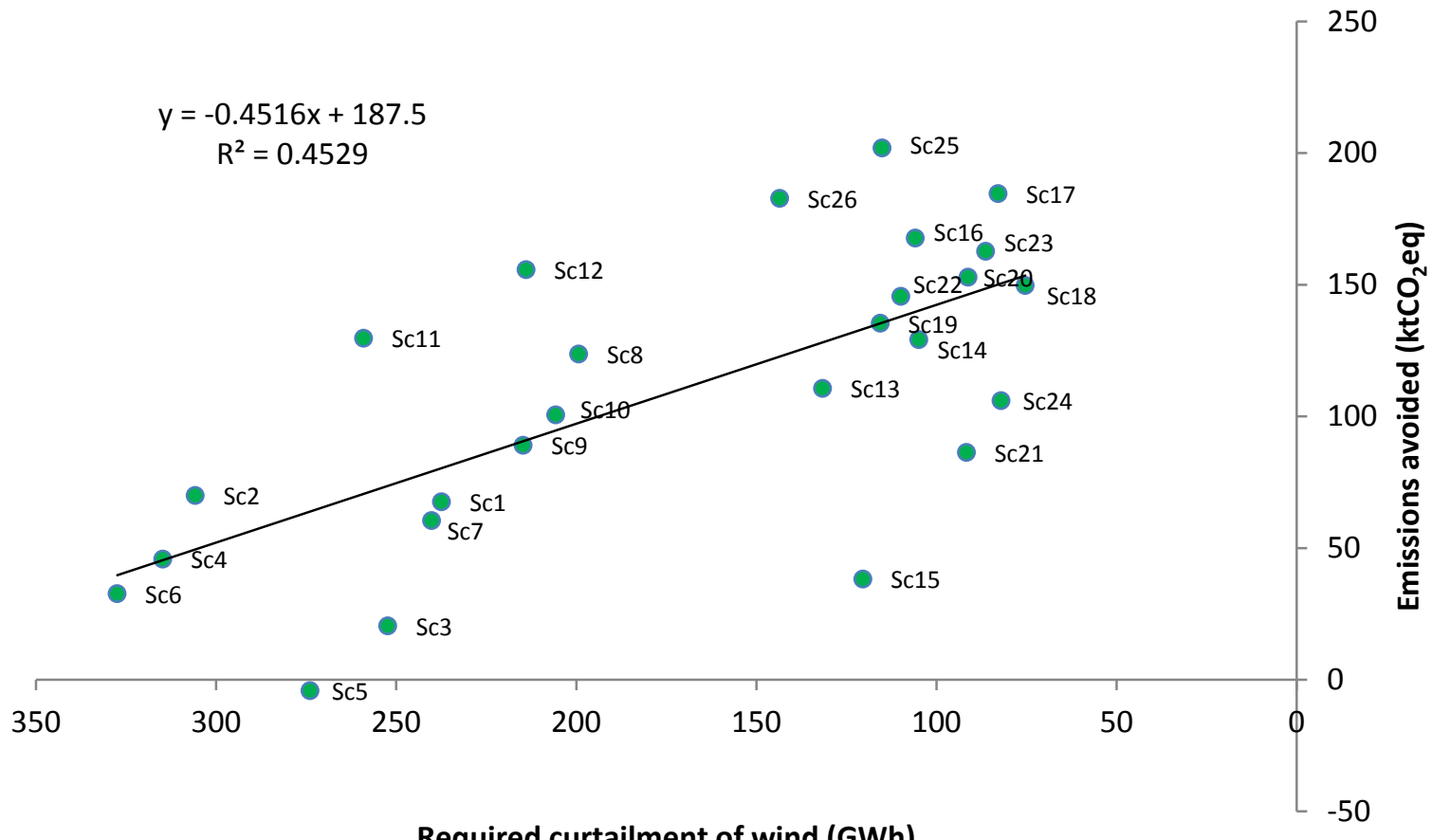

Figure 8 - Scatter plot showing the correlation between reducing wind curtailment and the savings on carbon emissions for each scenario

4.2. Wind ramping

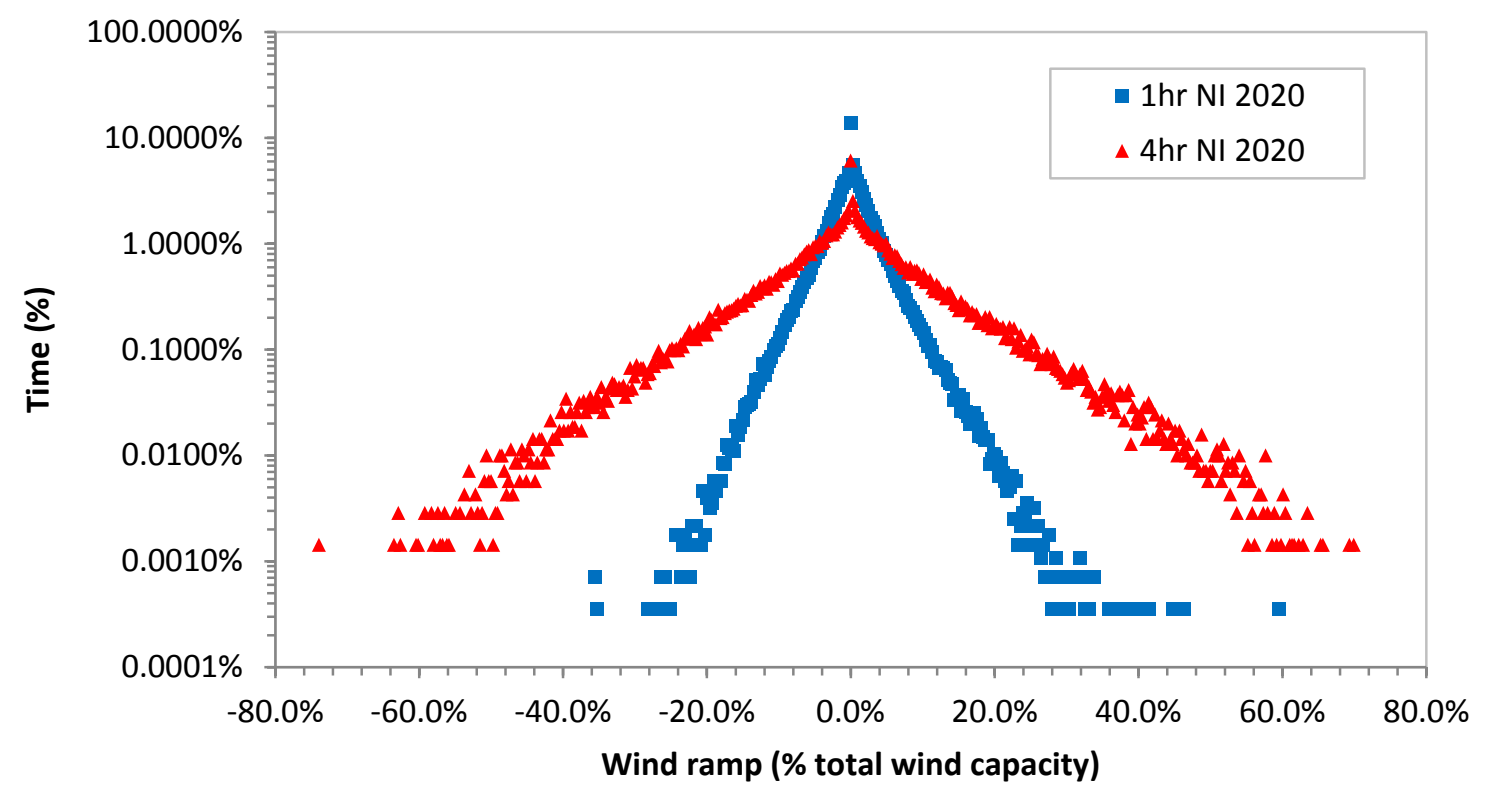

Figure 9 - Characteristics of wind variability in Northern Ireland for 2020 at one hour and four hour timescales

The size of changes in wind generation output over four-hour and one-hour timescales is mapped against their frequency of occurrence in Figure 9. Across the 32 years analysed, 
changes in wind generation remain less than $\pm 5 \%$ of installed capacity for approximately $99 \%$ of the time, but infrequent large swings in wind generation do occur. At a four-hour time step, these could be as large as $\pm 70 \%$ of installed wind capacity and $\pm 40 \%$ at a one-hour time step.

Over an hourly timescale, approximately $14 \%$ of the time wind generation output would remain unchanged. This characteristic is also prevalent over the four-hour time step, albeit with a lower frequency of $6 \%$.

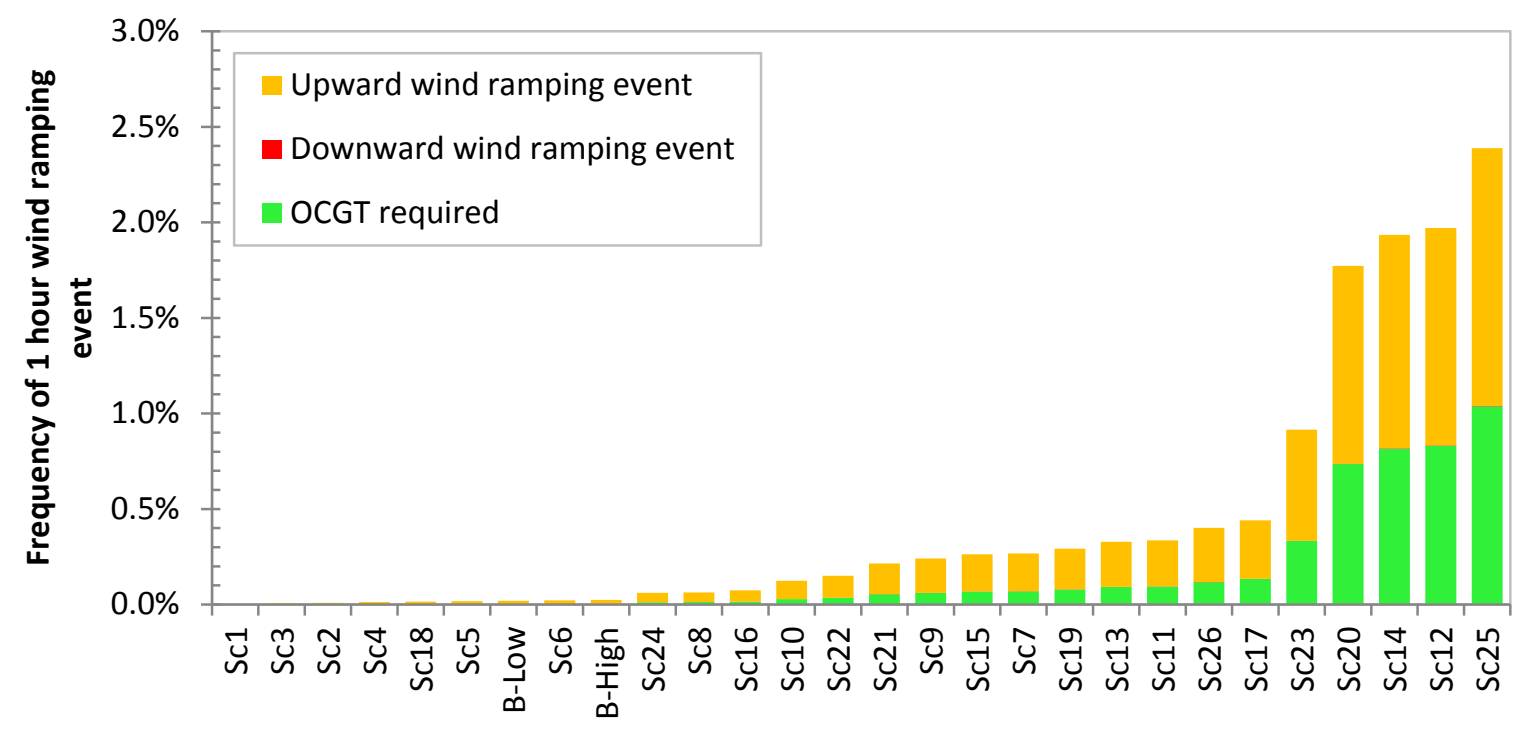

Figure 10 - Generator unit scenarios ranked by frequency of one-hour ramping periods outside of conventional generation ramping capabilities in Northern Ireland under 2020 levels of wind generation

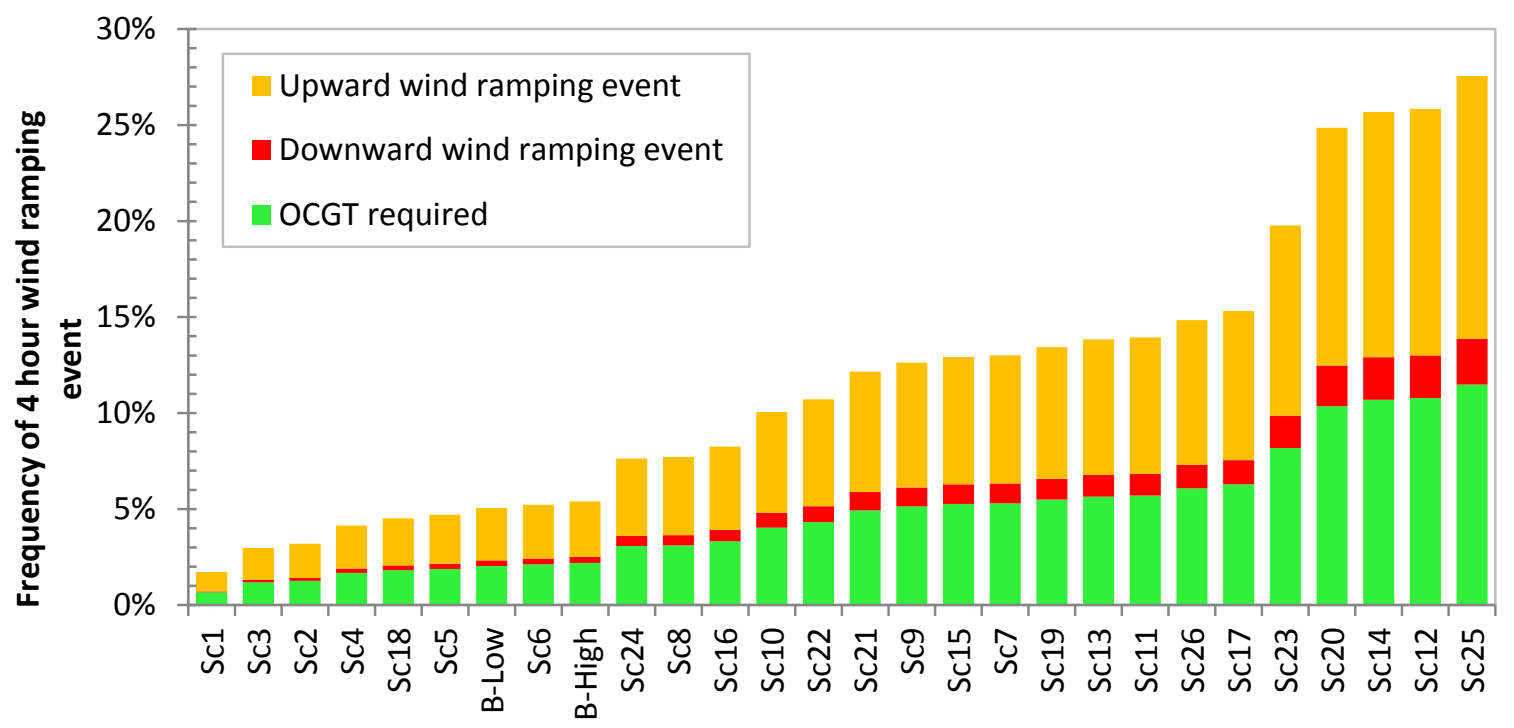

Figure 11 - Generator unit scenarios ranked by frequency of four-hour ramping periods outside of conventional generation ramping capabilities in Northern Ireland under 2020 levels of wind generation

Figure 10 and Figure 11 map the swings in wind generation against the capabilities of conventional plant in each of the 28 generator scenarios. The frequency of ramping occurrences that are outside of conventional generation capability is given for each. These are subcategorised into three types: a downward wind ramp that exceeds conventional plant 
ramping but that could be met by firing OCGT peaking generation (green); a downward wind ramp that exceeds combined conventional and OCGT peaking generation capacity (red); and upward wind ramping that exceeds the conventional plant's ability to ramp down its output in response (orange).

The analysis identifies a number of key issues surrounding the operational viability of 2020 levels of wind in Northern Ireland. The rankings reveal that the three unit combinations considered (B-Low, B-High and Sc1-6) have the lowest recorded number of potential ramping issues. The extent of the increase with two unit combinations (Sc7-26) depends on the particular combination of units and plant modifications considered. Of these two unit scenarios: Sc12, Sc14, Sc20, Sc23 and Sc25 all indicate notably higher occurrences of problematic ramping events. The common factor to these scenarios (Table 5) is the inclusion of unit B10, a small single shaft CCGT unit at Ballylumford power station with limited ramping range.

\section{Discussion and recommendations}

\subsection{Divergent requirements}

The challenge of wind ramping and the need to curtail excessive wind generation pose contradictory requirements for the system. Reducing the baseload conventional generation can significantly reduce the level and associated cost impact of wind curtailment. Curtailment could otherwise grow to 7-7.5\% of installed wind generation capacity in Northern Ireland, by 2020. One notable way to ease this would be to reduce the system security constraint that requires three generator units to remain on at all times, which increasing plant flexibility makes more feasible. These is an expectation that by 2020 these constraints will be relaxed as a result of increased plant flexibility, the development of grid scale battery storage [40], compressed air energy storage [41], and reinforcement of interconnection between the north and south [32]. However reducing the proportion of conventional generation at times of high wind also diminishes the capacity of dispatchable plant available to respond to swings in wind generation output.

A high level of ramping flexibility is needed to manage swings in wind generation. Upward wind ramping can be avoided by limiting the ramp rate of wind generation, and most downward wind ramp rates met by firing peaking generation. Both of these have associated balancing costs to the system. The remaining downward wind ramp events, outside of even peaking capacity, would require additional generation to be sourced - either by building new plant or running additional spinning reserve (with the impact of further increased curtailment), relying on interconnector import, or investment in energy storage. Whilst very rare, swings could be as large as $\pm 40 \%$ of wind capacity over one hour and $\pm 70 \%$ over four hours.

Over one-hour and four-hour timescales steam units in Northern Ireland demonstrate more value due to their greater ramping range, despite the conventional view that gas plants are the most useful for managing wind variability. This is because there are essentially two components to conventional plant flexibility - ramping range and ramping speed. Whilst gas power plants are able to ramp quickly, their range is more limited than the steam units in Northern Ireland, which can reach very low minimum generation levels. As Figure 10 and Figure 11 show, challenging wind ramps occur significantly more frequently at four-hour 
timescales than at one hour. Whilst wind ramping is larger at longer timescales (cf. Figure 9), steam generation can comfortably meet these rates of change (see Table 4). Thus, overall minimum to maximum output range and the timescales for bringing new plant online are more significant than the MW/min ramp rate. This contrasts with Deane et al's [26] All Island finding that even shorter timescale analysis requires increased attention to ramp rates. At one hour and above, a coal plant modified with improved range performs particularly well despite not being extremely fast to ramp.

Curtailment and ramping impacts could be eased by the modification of conventional plant running regimes to offer more flexibility. Alterations to the minimum amount of conventional plant synchronised to the grid during high periods of wind generation output reduced wind curtailment and emissions (Figure 9) and the occurrence of ramping events (Figure 10 and Figure 11). This is particularly prominent for scenarios where Kilroot operates on heavy fuel oil during these periods (K_O in Table 3) as it both significantly reduces the units' minimum generation and improves rate of ramping. Similarly, reducing the time to bring a plant online faster than the four-hour substitute reserve band specified in the Northern Ireland Grid Code [9] would significantly reduce ramping events.

\subsection{Flexibility opportunities and market restrictions}

Running regimes that reduce stable generation with coal or use oil-coal mixes provide reductions to wind curtailment. However, rather than any incentive for operating in this way, plant operators can even face a disincentive for making modifications to enable this. In Northern Ireland, an increasing portion of generators is displaced from in-merit operation by greater installed wind capacity and makes no profit when called to generate as constrained on units. More frequent running increases maintenance costs and lowers availability, which in turn reduces capacity payment as units are only paid for during times when they are available.

A benefit could be seen from market incentives for increased flexibility. For example, encouraging generators to offer reduced MSGs could diminish the need for load-balancing curtailment, whilst decreasing start up times could improve response to drop offs in wind generation. A possible vehicle for this is offering flexibility from constrained plant as a strategically tendered ancillary service, in a similar way that voltage regulation and black start capability are valued.

The market may also provide a natural incentive to increase power plant flexibility as renewable penetrations grow. When market prices become more volatile, periods where electricity price is lower than plant generating costs will become more frequent. During these periods, plants which can better reduce their overall output levels may have a competitive advantage.

Northern Ireland's security constraints significantly influence the level of wind curtailment required. Although modifications can be made to reduce the minimum generation of some units, Figure 6 and Figure 7 identified that the largest reductions to curtailment and savings to carbon emissions are achieved through relaxing these security constraints. Two unit combinations would result in notably lower curtailment during windy periods. In order to relax this rule it is important to address the inertial response on the system by improving plant Rate of Change of Frequency (ROCOF) capability, interconnection capacity, and/or provision of synthetic inertia from technologies like energy storage. 


\section{Conclusions}

This paper has examined a variety of steps that could be taken to enhance the flexibility of thermal plant operating in Northern Ireland, a sub-system of the Irish Single Electricity Market. Whilst the detailed modifications (outlined in Section 2.3) considered are necessarily market specific, the potential to increase flexibility brings implications for many established power systems evolving to incorporate increased levels of renewable generation. To differing degrees, changes to the operation of existing generation have been shown to reduce wind curtailment and increase resilience to wind ramping, as well as reducing associated $\mathrm{CO}_{2}$ emissions and costs. Significantly, interim solutions can be implemented without capital spending on new plant.

The management of wind curtailment and wind ramping pose potentially contradictory requirements for a system with high renewable penetration. Maximising the reduction of wind curtailment does not necessarily provide the greatest reduction to system cost or to carbon emissions, due to the efficiency characteristics of part loaded plant. In the system studied, plant output range was seen to be more important than the rate of ramping in responding to larger changes in wind generation output, particularly at longer (four-hour) timescales. This favours steam plant typified by larger operating ranges.

Operational and technical modifications have been considered for an exemplar coal plant, noting:

- The greatest system saving, achieved by modification for lower stable coal generation, reduced wind curtailment by $21.2 \mathrm{GWh}$ and costs by $£ 1.8 \mathrm{~m}$ for 2011 but in the worst case increased carbon emissions by $3.5 \mathrm{ktCO}_{2} \mathrm{eq}$ due to the reduced efficiency of part loaded coal outweighing the benefits of reduced wind curtailment.

- The greatest wind curtailment and carbon saving came from running on oil during periods of high wind generation, saving up to $20 \mathrm{ktCO}_{2}$ eq per annum and reducing up to 26.1GWh of wind curtailment. This would improve ramping capability but slightly increase overall system cost given the high commodity price of heavy fuel oil.

- The option with least barriers to implementation, requiring no physical modification, is a blend of coal firing with continual oil support during times of high wind generation. This would offer intermediate reductions to wind curtailment, system operating costs and carbon emissions.

Whole system costs may be higher than necessary if markets do not effectively value the flexibility of conventional plant. Market rules can require certain conventional units to run to maintain system security, for limited financial returns. This serves to disincentivise investment in plant that is regularly 'constrained on'. At the same time, operation options such as fuel switching or blending are restricted by present market rules, in this case, the requirement for monotonic pricing.

The unit-by-unit approach used in this study has highlighted specific plant modification and operation opportunities that might otherwise have been overlooked; however, this would be an inefficient approach for larger energy systems. Closer attention to plant characteristics is recommended when deploying power systems models, commonly used for such analysis. Alongside rule of thumb approaches such as non-synchronous generation limits, close consideration is needed to assumptions that would allow for fuel switching, plant modification etc. Especially close care is recommended where local constraints are applied to small systems, or sensitive, semi-isolated parts of larger networks. 


\section{Acknowledgements}

Whilst the authors worked closely with conventional plant operators in Northern Ireland, the research was conducted impartially and represents our own individual views. The authors would like to express their thanks in particular to Mark Miller and Brian Mongan of AES, as well as the commercial and operations teams at Kilroot and Ballylumford power stations for their operational insight and provision of data. Our thanks to AES for their funding contribution to this doctoral research project and to EPSRC for funding the Technologies for Sustainable Built Environments (TSBE) Centre (grant number EP/G037787/1).

\section{References}

[1] EirGrid and SONI, “Tranmission Constraint Groups: March 2012.” Mar-2012.

[2] DETINI, “A strategic framework for Northern Ireland.” Sep-2010.

[3] D. Connolly, H. Lund, B. V. Mathiesen, E. Pican, and M. Leahy, "The technical and economic implications of integrating fluctuating renewable energy using energy storage,” Renewable Energy, vol. 43, pp. 47-60, Jul. 2012.

[4] A. Tuohy and M. O'Malley, "Pumped storage in systems with very high wind penetration,” Energy Policy, vol. 39, no. 4, pp. 1965-1974, Apr. 2011.

[5] P. Denholm and M. Hand, "Grid flexibility and storage required to achieve very high penetration of variable renewable electricity,” Energy Policy, vol. 39, no. 3, pp. 18171830, Mar. 2011.

[6] R. Bove, M. Bucher, and F. Ferretti, "Integrating large shares of wind energy in macroeconomical cost-effective way,” Energy, vol. 43, no. 1, pp. 438-447, Jul. 2012.

[7] K. De Vos, A. G. Petoussis, J. Driesen, and R. Belmans, "Revision of reserve requirements following wind power integration in island power systems," Renewable Energy, vol. 50, pp. 268-279, Feb. 2013.

[8] L. Hong, H. Lund, and B. Möller, "The importance of flexible power plant operation for Jiangsu’s wind integration,” Energy, vol. 41, no. 1, pp. 499-507, May 2012.

[9] SONI, "SONI Grid Code.” 22-Feb-2011.

[10] H. Klinge Jacobsen and S. T. Schröder, "Curtailment of renewable generation: Economic optimality and incentives," Energy Policy.

[11] D. J. Burke and M. J. O’Malley, "Transmission connected wind curtailment with increasing wind capacity connection,” in IEEE Power Energy Society General Meeting, 2009. PES '09, 2009, pp. 1 -5.

[12] A. Kalantari and F. D. Galiana, "The impact of wind power variability and curtailment on ramping requirements," in Transmission and Distribution Conference and Exposition: Latin America (T D-LA), 2010 IEEE/PES, 2010, pp. 133 -138.

[13] D. J. Burke and M. J. O’Malley, “Factors Influencing Wind Energy Curtailment,” IEEE Transactions on Sustainable Energy, vol. 2, no. 2, pp. 185 -193, Apr. 2011.

[14] E. V. Mc Garrigle, J. P. Deane, and P. G. Leahy, "How much wind energy will be curtailed on the 2020 Irish power system?," Renewable Energy, vol. 55, pp. 544-553, Jul. 2013.

[15] C. Brandstätt, G. Brunekreeft, and K. Jahnke, "How to deal with negative power price spikes?-Flexible voluntary curtailment agreements for large-scale integration of wind," Energy Policy, vol. 39, no. 6, pp. 3732-3740, Jun. 2011. 
[16] T. Brijs, K. De Vos, C. De Jonghe, and R. Belmans, "Statistical analysis of negative prices in European balancing markets," Renewable Energy, vol. 80, pp. 53-60, Aug. 2015.

[17] A. J. Lamadrid and T. Mount, "Ancillary services in systems with high penetrations of renewable energy sources, the case of ramping," Energy Economics, vol. 34, no. 6, pp. 1959-1971, Nov. 2012.

[18] J. Gostling, "Two Shifting of Power Plant: Damage to Power Plant Due to Cycling - A brief overview,” OMMI Journal, vol. 1, no. 1, Apr. 2002.

[19] C. Kamath, "Associating weather conditions with ramp events in wind power generation," in Power Systems Conference and Exposition (PSCE), 2011 IEEE/PES, 2011, pp. $1-8$.

[20] R. Hewston and S. R. Dorling, “An analysis of observed daily maximum wind gusts in the UK," Journal of Wind Engineering and Industrial Aerodynamics, vol. 99, no. 8, pp. 845-856, Aug. 2011.

[21] M. Y. Hwang, C. H. Jin, Y. K. Lee, K. D. Kim, J. H. Shin, and K. H. Ryu, "Prediction of wind power generation and power ramp rate with time series analysis," in $20113 r d$ International Conference on Awareness Science and Technology (iCAST), 2011, pp. 512 $-515$.

[22] B. C. Ummels, M. Gibescu, E. Pelgrum, W. L. Kling, and A. J. Brand, "Impacts of Wind Power on Thermal Generation Unit Commitment and Dispatch," IEEE Transactions on Energy Conversion, vol. 22, no. 1, pp. 44 -51, Mar. 2007.

[23] D. Milborrow, "Wind power on the grid," in Renewable electricity and the grid: the challenge of variability, G. Boyle, Ed. Earthscan, 2007, pp. 31-54.

[24] ILEX and G. Strbac, "Qualifying the system costs of additional renewables in 2020," UMIST, A Report to the Department of Trade and Industry., Oct. 2002.

[25] D. Milborrow, "Penalties for intermittent sources of energy," PIU Working Paper on Penalties, Cabinet Office, 2001.

[26] J. P. Deane, G. Drayton, and B. P. Ó Gallachóir, “The impact of sub-hourly modelling in power systems with significant levels of renewable generation,” Applied Energy, vol. 113, pp. 152-158, Jan. 2014.

[27] A. Arabali, M. Ghofrani, M. Etezadi-Amoli, and Y. Baghzouz, "Ramping requirements and operation cost in a power system with dispersed wind generation," in Transmission and Distribution Conference and Exposition (T D), 2012 IEEE PES, 2012, pp. 1 -7.

[28] A. M. Foley, B. P. Ó Gallachóir, E. J. McKeogh, D. Milborrow, and P. G. Leahy, "Addressing the technical and market challenges to high wind power integration in Ireland,” Renewable and Sustainable Energy Reviews, vol. 19, no. 0, pp. 692-703, Mar. 2013.

[29] A. Tuohy and M. O’Malley, "Pumped storage in systems with very high wind penetration,” Energy Policy, vol. 39, no. 4, pp. 1965-1974, Apr. 2011.

[30] A. Tuohy, M. Bazilian, R. Doherty, B. Ó. Gallachóir, and M. O’Malley, "Burning peat in Ireland: An electricity market dispatch perspective,” Energy Policy, vol. 37, no. 8, pp. 3035-3042, Aug. 2009.

[31] EirGrid and SONI, “DS3 Programme,” 2012. [Online]. Available: http://www.soni.ltd.uk/Operations/DS3/. [Accessed: 05-Aug-2014].

[32] EirGrid and SONI, “All Island Generation Capacity Statement 2014-2023.” 2014.

[33] BBC, "Interconnector energy shortage fears,” BBC, 26-Jun-2014.

[34] C. Thomson, "Do wind farms really reduce CO2 emissions? Greenhouse gas emissions savings from wind power.," presented at the SET for Britain, Westminster, London, 2013. 
[35] M. L. Kubik, P. J. Coker, and C. Hunt, "The role of conventional generation in managing variability,” Energy Policy, vol. 50, pp. 253-261, 2012.

[36] M. Lenzen, "Life cycle energy and greenhouse gas emissions of nuclear energy: A review," Energy Conversion and Management, vol. 49, pp. 2178-2199, 2008.

[37] SEMO, "Single Electricty Market Operator Market Data," http://www.sem-o.com/, 08Dec-2009. [Online]. Available: http://www.sem-o.com/Pages/default.aspx. [Accessed: 20-Aug-2014].

[38] EirGrid and SONI, “All Island Generation Capacity Statement 2011-2020,” 2010.

[39] M. L. Kubik, D. J. Brayshaw, P. J. Coker, and J. F. Barlow, "Exploring the role of reanalysis data in simulating regional wind generation variability over Northern Ireland," Renewable Energy, vol. 57, pp. 558-561, Sep. 2013.

[40] Belfast Telegraph, "Europe's biggest wind battery to slash cost of Northern Ireland electricity bills,” BelfastTelegraph.co.uk, 07-Feb-2015. [Online]. Available: http://www.belfasttelegraph.co.uk/news/northern-ireland/europes-biggest-wind-batteryto-slash-cost-of-northern-ireland-electricity-bills-30971106.html. [Accessed: 18-Mar2015].

[41] AgendaNI, "Northern Ireland to become the innovation hub for energy storage," agendaNi, Aug-2014. . 